\title{
Implementasi Metode Certainty Factor pada Sistem Pakar Bimbingan Konseling Siswa Bermasalah
}

\section{Implementation of Certainty Factor Method on Problematic Student Counseling Guidance Expert System}

\author{
Zilullah Nazir Hadi ${ }^{1}$, Dyah Susilowati²*, Hairani Hairani ${ }^{3}$, Muhammad Innuddin ${ }^{4}$ \\ $1,2,3,4$ Universitas Bumigora \\ Zilullah792@gmail.com¹, dyah.susilowati@universitasbumigora.ac.id²*, \\ hairani@universitasbumigora.ac.id ${ }^{3}$,inn@universitasbumigora.ac.id ${ }^{4}$
}

Submitted: 10 November 2021, Revised: 15 November 2021, Accepted: 23 November 2021

\begin{abstract}
Abstrak - Hal utama dalam pengembangan pendidikan adalah kualitas pendidikan. Salah satu yang menjadi penentu kualitas pendidikan adalah bimbingan konseling. Permasalahan selama ini adalah Sebagian besar siswa yang memiliki permasalahan merasa malu dalam melakukan bimbingan konseling langsung kepada guru BK dan biasanya melakukan konsultasi kepada temannya sehingga tidak dapat menyelesaikan permasalahan yang dihadapi. Hal tersebut membuat guru BK kesulitan untuk menangani permasalahan siswanya, sehingga dibutuhkan sebuah sistem yang dapat membantu dan memecahkan permasalahan yang di alami oleh siswa. Tujuan penelitian ini adalah merancang sistem pakar yang mengatasi permasalahan yang diderita oleh siswa menggunakan metode certainty factor yang dapat memberikan solusi berdasarkan jenis permasalahan yang diderita siswanya. Metodologi pengembangan sistem pakar pada penelitian ini menggunakan metodologi waterfall yang terdiri dari analisa kebutuhan, perancangan, pengkodean, dan pengujian. Hasil dari penelitian ini berupa aplikasi sistem pakar bimbingan konseling siswa bermasalah yang menerapkan metode certainty factor berbasis web yang dapat memudahkan siswa untuk mengetahui jenis permasalahan yang dihadapi berdasarkan gejala permasalahan yang dimasukkan. Kesimpulan dari penelitian ini adalah aplikasi sistem pakar yang dibangun memiliki tingkat kemudahan berdasarkan hasil usabiliti menggunakan metode SUS (System Usability Scale) sebesar 76,5\% atau baik bagi siswanya, sedangkan tingkat kemudahan bagi guru BK sebesar $\mathbf{9 2 , 7 0 \%}$ atau sangat baik .
\end{abstract}

Kata Kunci: bimbingan siswa bermasalah, sistem pakar, faktor kepastian.

\begin{abstract}
The main thing in the development of education is the quality of education. One of the determinants of the quality of education is counseling guidance. The problem so far is that most students who have problems feel embarrassed in doing counseling directly to the BK teacher and usually consult with their friends so that they cannot solve the problems they face. This makes it difficult for BK teachers to deal with student problems, so we need a system that can help and solve problems experienced by students. The purpose of this study is to design an expert system that overcomes the problems suffered by students using the certainty factor method that can provide solutions based on the types of problems suffered by the students. The expert system development methodology in this study uses the waterfall methodology which consists of needs analysis, design, coding, and testing. The result of this research is in the form of an expert system application for counseling problem students who apply a web-based certainty factor method that can make it easier for students to find out the types of problems they face based on the problems symptoms entered. The conclusion of this study is that the expert system application that was build has a level of convenience based on usability results using the SUS (System Usability Scale) method of $\mathbf{7 6 . 5 \%}$ or good for students, while the level of easiness for BK teachers is $\mathbf{9 2 . 7 0 \%}$ or very good.
\end{abstract}

Keywords: guidance for problematic students, expert systems, certainty factor.

Jurnal Bumigora Information Technology (BITe)

Vol.3, No.2, Desember 2021, pp. 97-106

ISSN: $2685-4066$

DOI: $10.30812 /$ bite.v3i2.1553 


\section{Pendahuluan}

Hal terpenting dalam pengembangan pendidikan adalah kualitas pendidikan. Kualitas akan menentukan sebaik apa cara dalam belajar dan manfaat apa yang akan mereka peroleh dari pendidikan tersebut. Salah satu faktor yang menjadi penentu kualitas pendidikan adalah bimbingan konseling. Guru bimbingan konseling bertugas untuk membantu dan mengarahkan siswa, sehingga setiap harinya guru bimbingan dan konseling akan berhadapan dengan berbagai macam karekteristik siswa. Bimbingan konseling merupakan mata pelajaran yang bertujuan untuk memberi bantuan kepada siswa untuk mencapai kemandiriannya dalam pemahaman diri, sehingga siswa sanggup mengarahkan dirinya sesuai dengan tuntunan yang ada. Menurut guru BK SMPN 4 Mataram Ibu Mistiani permasalahan selama ini adalah sebagian besar siswa merasa malu dalam melakukan bimbingan dan konseling secara langsung, sehingga banyak siswa melakukan konsultasi terkait tentang masalah mereka kepada temannya. Akibatnya permasalahan yang dialami siswa tersebut sulit untuk diselesaikan. Oleh karena itu, guru bimbingan dan konseling atau BK merasa sulit untuk dapat membantu siswa-siswi tersebut dalam menyelesaikan masalah yang dialami.

Dari pertimbangan masalah di atas maka dibutuhkan sebuah aplikasi yang dapat membantu menganalisis dan memberikan solusi atas permasalahan yang dihadapi para siswa dalam melakukan bimbingan dan konseling. Salah satu cara dalam membantu masalah diatas adalah membuat aplikasi web berbasis sistem pakar. Sistem pakar adalah sebuah sistem yang berusaha mengadopsi atau meniru pengetahuan seorang pakar ke dalam komputer, agar komputer dapat menyelesaikan permasalahan layaknya seorang pakar atau ahli [1]. Sistem pakar sendiri memiliki banyak metode dalam menyelesaikan permasalahan tertentu seperti diagnosis jenis rematik berbasis metode forward chaining [2], certainty factor [3], penyakit THT menggunakan certainty factor [4], dan diagnosis penyakit skizofrenia dengan dempster shafer [5].

Pada pembuatan sistem pakar ini metode yang digunakan adalah metode certainty factor. Metode certainty factor dipilih karena metode ini cocok dalam proses penentuan identifikasi masalah-masalah yang ada pada siswa dan hasilnya dalam bentuk nilai persentase tingkat kepastian. Metode certainty factor dapat menjelaskan tentang tingkat kepastian terhadap suatu fakta atau aturan yang menggambarkan ukuran keyakinan dari seorang pakar terhadap masalah yang sedang dihadapi [6]. Metode certainty factor menggunakan nilai untuk mengasumsikan tingkat kepercayaan para ahli atau pakar terhadap suatu nilai [7]. Oleh karena itu, penelitian ini bertujuan untuk merancang sistem pakar yang mengatasi permasalahan yang diderita oleh siswa menggunakan metode certainty factor yang dapat memberikan solusi berdasarkan jenis permasalahan yang diderita siswa dalam bentuk aplikasi berbasis web dengan php dan mysql.

\section{Metode Penelitian}

Penelitan ini menggunakan metode pengumpulan data untuk mendapatkan data yang digunakan dan metodologi waterfall untuk perancangan sistem pakar untuk bimbingan konseling pada siswa bermasalah SMP Negeri 4 Mataram yang tahapannya ditunjukkan pada Gambar 1.

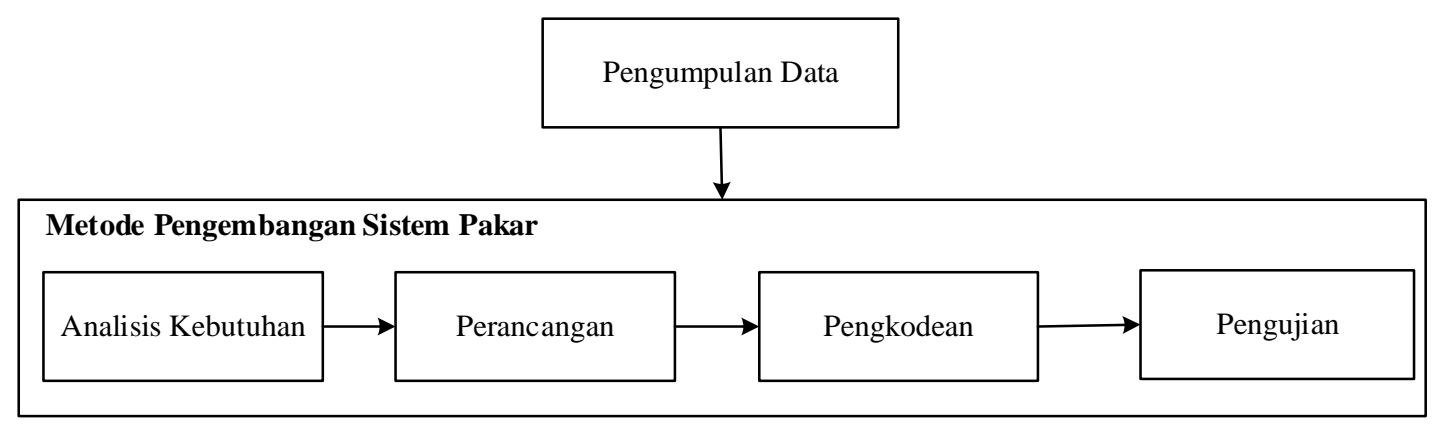

Gambar 1. Tahapan Penelitian

https://journal.universitasbumigora.ac.id/index.php/bite ISSN: 2685-4066 
Berdasarkan Gambar 1 terdapat 2 tahapan yaitu tahapan pertama adalah pengumpulan data yang dapat digunakan untuk mengumpulkan data yang diperlukan seperti data kebutuhan sistem, data permasalahan siswa, dan data gejala permasalahan. Tahapan kedua adalah pengembangan sistem pakar berbasis web menggunakan metode waterfall yang terdiri dari analisis kebutuhan, perancangan, pengkodean, dan pengujian.

\subsection{Pengumpulan Data}

Pada tahapan ini dilakukan pengumpulan data dengan melakukan wawancara langsung dengan guru BK SMP Negeri 4 Mataram atas nama Ibu Mistiani. Data yang dikumpulkan berupa permasalahan bimbingan konseling siswa, data kebutuhan sistem, data permasalahan, dan data gejala permasalahan.

\subsection{Analisis Kebutuhan Sistem}

Pada tahapan ini akan dijelaskan kebutuhan sistem yang ada pada aplikasi sistem pakar yang akan dibuat berdasarkan wawancara dengan guru BK SMP Negeri 4 Mataram. Ada 2 pengguna pada aplikasi yang dikembangkan yaitu Guru BK dan Siswa yang memiliki hak akses berbeda untuk mengakses kebutuhan sistemnya yang ditunjukkan pada Tabel 1.

Tabel 1. Analisis Kebutuhan Sistem

\begin{tabular}{cc}
\hline Pengguna & Kebutuhan Sistem \\
\hline Guru BK & Terdapat fitur login \\
& Mengelola data histori konsultasi \\
& Mengelola data permasalahn \\
& Mengelola data gejala permasalahan \\
& Mengelola data basis pengetahuan \\
Siswa & Melakukan konsultasi \\
\hline
\end{tabular}

\subsection{Perancangan}

Pada tahapan ini dilakukan pemodelan terhadap data yang sudah didapatkan pada fase sebelumnya ke dalam Tabel Keputusan agar mudah dipahami. Adapun hasil pemodelan data ke dalam Tabel Keputusan ditunjukkan pada Tabel 2, Tabel 3, dan Tabel 4.

Tabel 2. Data Permasalahan

\begin{tabular}{ccc}
\hline No & Permasalahan & Kode Permasalahn \\
\hline 1. & Malas atau kurangnya motivasi belajar & P-001 \\
2. & Kesulitan berkonsentrasi dalam belajar & P-002 \\
3. & Menyontek & P-003 \\
4. & Tidak memahami pelajaran & P-004 \\
5. & Merasa berat dalam mengerjakan tugas & P-005 \\
6. & Telat dalam mengumpulkan tugas atau tidak & P-006 \\
& dapat mengumpulkan tugas & \\
\hline
\end{tabular}

Tabel 3. Data Gejala Permasalahan

\begin{tabular}{clcc}
\hline $\begin{array}{c}\text { Kode } \\
\text { Permasalahan }\end{array}$ & \multicolumn{1}{c}{ Penyebab } & $\begin{array}{c}\text { Kode } \\
\text { Penyebab }\end{array}$ & CF \\
\hline P-001 & Kesulitan memahami dalam mata pelajaran tertentu & G-001 & 0.8 \\
P-001. & Lingkungan dan sarana kurang kondusif & G-004 & 0.8 \\
P-001 & Tidak memiliki motivasi belajar & G-002 & 0.6 \\
P-002 & Kurangnya konsentasi & G-008 & 0.8 \\
P-002 & Lingkungan dan sarana kurang kondusif & G-004 & 0.8 \\
P-002 & Tidak menyukai mata pelajaran & G-003 & 0.6 \\
P-003 & Kurang percaya diri & G-014 & 0.8 \\
P-003 & Merasa tidak mampu dalam menyelesaikan tugas & G-006 & 0.8 \\
P-003 & Terlalu banyak tugas yang diberikan & G-010 & 0.6 \\
P-003 & Tidak dapat menguasai materi pelajaran & G-007 & 0.8 \\
P-003 & Tidak menyukai mata pelajaran tertentu & G-003 & 1 \\
P-003 & Waktu mengumpulkan sedikit & G-013 & 0.2 \\
P-004 & Hilang semangat belajar & G-015 & 0.2 \\
\hline
\end{tabular}

https://journal.universitasbumigora.ac.id/index.php/bite 


\begin{tabular}{|c|c|c|c|}
\hline $\begin{array}{c}\text { Kode } \\
\text { Permasalahan }\end{array}$ & Penyebab & $\begin{array}{c}\text { Kode } \\
\text { Penyebab }\end{array}$ & $\overline{\mathrm{CF}}$ \\
\hline P-004 & Kurang kesempatan waktu belajar & G-009 & 0.8 \\
\hline P-004 & Kurangnya konsentrasi & G-008 & 0.8 \\
\hline P-004 & Lingkungan dan sarana kurang kondusif & G-004 & 0.6 \\
\hline P-004 & Malu atau tidak dapat bertanya materi pelajaran & G-012 & 1 \\
\hline P-004 & Tidak dapat menguasai materi pelajaran & G-007 & 0.8 \\
\hline P-005 & Lingkungan dan sarana kurang kondusif & G-004 & 0.2 \\
\hline P-005 & Kesulitan dalam mata pelajaran tertentu & G-001 & 0.6 \\
\hline P-005 & Terlalu banyak tugas yang diberikan & G-010 & 0.8 \\
\hline $\mathrm{P}-005$ & Tidak memiliki motivasi belajar & G-002 & 0.2 \\
\hline P-005 & Waktu mengumpulkan sedikit & G-013 & 0.8 \\
\hline P-006 & Merasa tidak mampu dalam menyelesaikan tugas & G-006 & 0.4 \\
\hline P-006 & Suka menunda-nunda & G-011 & 0.8 \\
\hline P-006 & Terlalu banyak tugas yang diberikan & G-010 & 1 \\
\hline $\mathrm{P}-006$ & Tidak dapat menguasai materi pelajaran & G-007 & 0.6 \\
\hline P-006 & Tidak mengerjakan tugas dalam mata pelajaran tertentu & G-005 & 0.4 \\
\hline P-006 & Waktu mengumpulkan sedikit & G-013 & 1 \\
\hline
\end{tabular}

Tabel 4. Data Basis Pengetahuan

\begin{tabular}{ccccccc}
\hline Kode Penyebab / Kode Permasalahan & P-001 & P-002 & P-003 & P-004 & P-005 & P-006 \\
\hline G-001 & $\checkmark$ & & & $\checkmark$ & $\checkmark$ & \\
G-002 & $\checkmark$ & & & & $\checkmark$ & \\
G-003 & $\checkmark$ & $\checkmark$ & & & & \\
G-004 & & & $\checkmark$ & $\checkmark$ & $\checkmark$ \\
G-005 & & $\checkmark$ & & & $\checkmark$ \\
G-006 & & $\checkmark$ & $\checkmark$ & & $\checkmark$ \\
G-007 & & & $\checkmark$ & & \\
G-008 & & $\checkmark$ & & $\checkmark$ & $\checkmark$ \\
G-009 & & & & & $\checkmark$ \\
G-010 & & & $\checkmark$ & & $\checkmark$ \\
G-011 & & $\checkmark$ & & $\checkmark$ & $\checkmark$ \\
G-012 & & $\checkmark$ & & & \\
G-013 & & & & & \\
G-014 & & & & & & \\
\end{tabular}

\subsection{Pengkodean}

Pada tahapan ini dilakukan pembuatan aplikasi bimbingan konseling siswa bermasalah berbasis web dan mysql berdasarkan analisa kebutuhan dan perancangan yang dibuat sebelumnya. Metode yang digunakan untuk mengetahui tingkat kepastian siswa mengalami jenis permasalahan yang dihadapi adalah metode certainty factor. Metode certainty factor merupakan sebuah metode yang dapat menggambarkan tingkat keyakinan ahli atau pakar terhadap suatu permasalahan [8]. Ada dua cara untuk mendapatkan nilai tingkat keyakinan (CF) yaitu berbasis nilai kepercayaan atau ketidakpercayaan, serta wawancara seorang pakar [9]. Pada penelitian ini menggunakan cara wawancara seorang pakar untuk mendapatkan nilai tingkat keyakinannya dan bobot tingkat keyakinannya yang dimasukkan seorang user. Formula metode certainty factor yang digunakan pada penelitian ini ditunjukkan pada persamaan (1) untuk evidence $\mathrm{E}$ tunggal dan Hipotesis $\mathrm{H}$ tunggal dan persamaan (2) untuk kombinasi dua buah rule dengan evidence berbeda ( $E_{1}$ dan $E_{2}$ ) namun hipotesis sama [10].

$$
\begin{aligned}
& C F(H, E)=C F(E) * C F(\text { rule }) \\
& C F\left(C F_{1}, C F_{2}\right)=C F_{1} * C F_{2}\left(1-C F_{1}\right) \quad \text { jika } \mathrm{CF}_{1}>0 \text { dan } \mathrm{CF}_{2}>0
\end{aligned}
$$

\subsection{Pengujian}

SUS merupakan metode dalam menguji usability system computer dengan menggunakan kuisioner. Metode SUS memiliki 10 macam pertanyaan yang masing-masing pertanyaan tersebut menggunakan skala likert sebagai tanggapan. Adapun daftar pertanyaan menggunakan metode SUS ditunjukkan pada Tabel 5. 
Tabel 5. Daftar Pertanyaan SUS

\begin{tabular}{|c|c|c|c|c|c|c|}
\hline \multirow{3}{*}{ No. } & \multirow{3}{*}{ Pertanyaan } & \multicolumn{5}{|c|}{ Tanggapan } \\
\hline & & SS & $\mathbf{S}$ & RG & TS & STS \\
\hline & & 5 & 4 & 3 & 2 & 1 \\
\hline 1. & Saya berpikir akan menggunakan sistem ini lagi & & & & & \\
\hline 2. & Saya berpikir sistem ini rumit untuk digunakan & & & & & \\
\hline 3. & Saya berpikir sistem ini mudah digunakan & & & & & \\
\hline 4. & $\begin{array}{l}\text { Saya membutuhkan bantuan dari orang lain atau } \\
\text { teknisi dalam menggunakan sistem ini. }\end{array}$ & & & & & \\
\hline 5. & $\begin{array}{l}\text { Saya berpikir fitur-fitur sistem ini berjalan } \\
\text { dengan semestinya. }\end{array}$ & & & & & \\
\hline 6. & $\begin{array}{l}\text { Saya berpikir ada banyak hal yang tidak } \\
\text { konsisten (tidak serasi pada sistem ini) }\end{array}$ & & & & & \\
\hline 7. & $\begin{array}{l}\text { Saya berpikir orang lain akan memahami cara } \\
\text { menggunakan sistem ini dengan cepat. }\end{array}$ & & & & & \\
\hline 8. & Saya berpikir sistem ini membingungkan & & & & & \\
\hline 9. & $\begin{array}{l}\text { Saya berpikir tidak ada hambatan dalam } \\
\text { menggunakan sistem ini. }\end{array}$ & & & & & \\
\hline 10. & $\begin{array}{l}\text { Saya perlu membiasakan diri terlebih dahulu } \\
\text { sebelum menggunakan sistem ini. }\end{array}$ & & & & & \\
\hline
\end{tabular}

SUS memiliki output berupa skor yang mudah dipahami dengan range skor dari 0 sampai dengan 100, semakin besar skor SUS maka semakin baik usability-nya [11].

\section{Hasil dan Pembahasan}

Pada tahapan ini sudah dibuat aplikasi sistem pakar bimbingan konseling bermasalah menggunakan metode certainty factor dalam bentuk aplikasi berbasis web dengan php dan mysql.

\subsection{Implementasi Sistem}

Pada tahapan ini dijelaskan tampilan aplikasi yang sudah dibuat berdasarkan perancangan sebelumnya.

\subsubsection{Tampilan Halaman Login}

Tampilan halaman login adalah halaman yang digunakan pengguna Guru BK memasukkan username dan password agar dapat mengakses halaman utama. Pada halaman ini juga terdapat menu lupa password yang berguna untuk menyetel ulang password jika lupa password-nya. Adapun tampilan halaman login ditunjukkan pada Gambar 2.

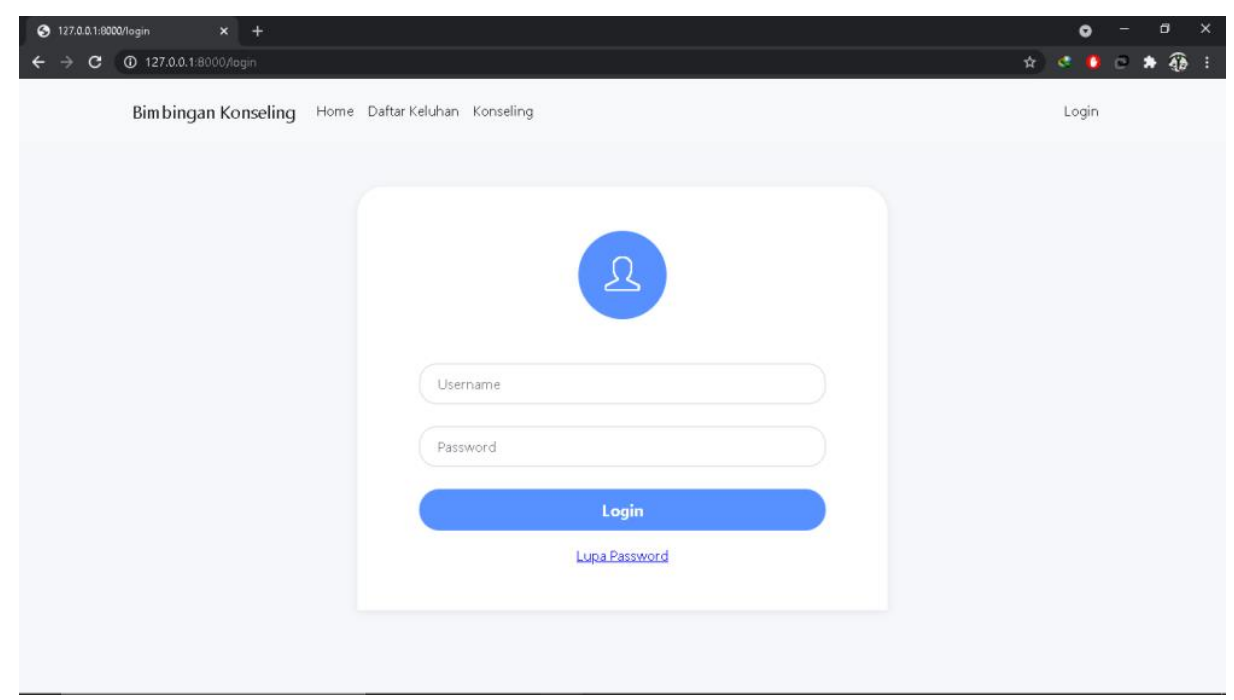

Gambar 2. Tampilan Halaman Login

https://journal.universitasbumigora.ac.id/index.php/bite

ISSN: 2685-4066 


\subsubsection{Tampilan Halaman Utama User}

Setelah user Guru BK berhasil login pada halaman login, akan langsung diarahkan ke halaman utama yang dapat digunakan oleh Guru BK untuk kelola data permasalahan, data gejala permasalahan, data basis pengetahuan, dan data konsultasi. Tampilan halaman utama Guru BK ditunjukkan pada Gambar 3.

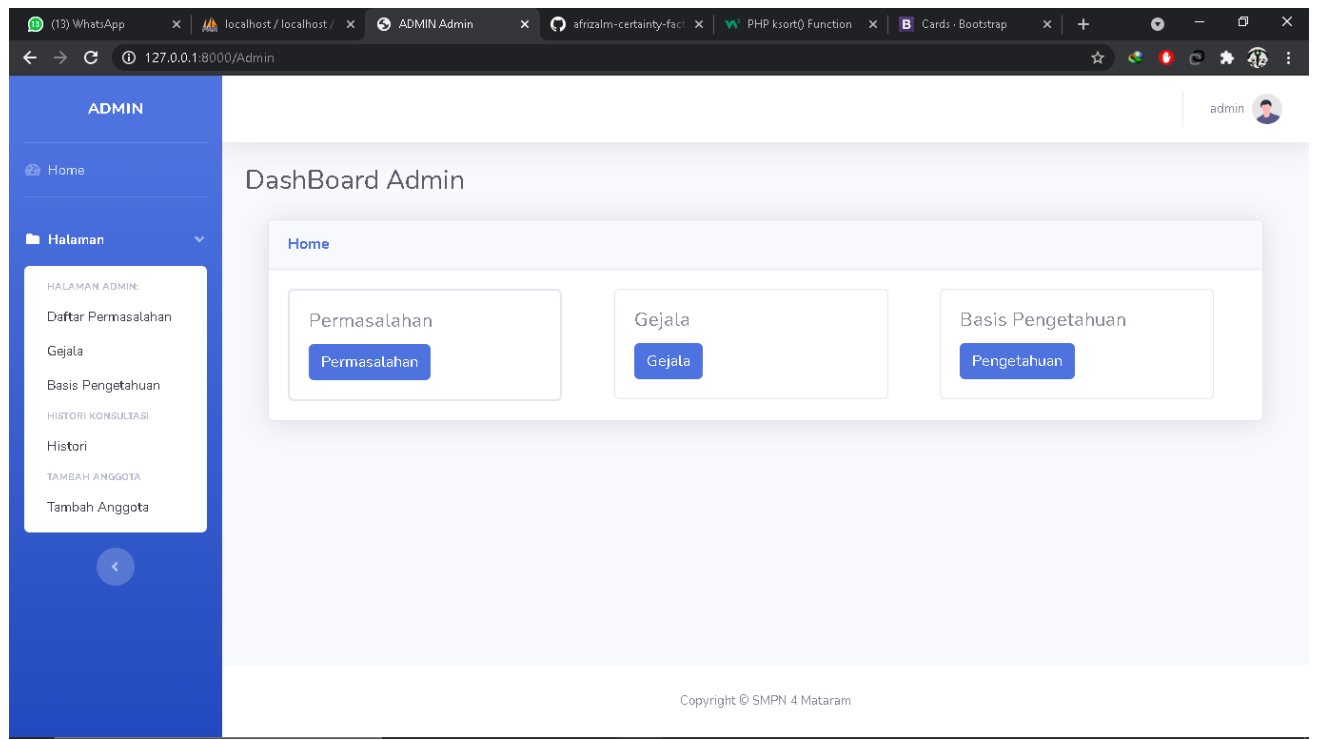

Gambar 3. Tampilan Halaman Utama Guru BK

\subsubsection{Tampilan Halaman Data Permasalahan}

Pada halaman ini Guru BK dapat melakukan input, edit, dan hapus data permasalahan yang ditunjukkan pada Gambar 4.

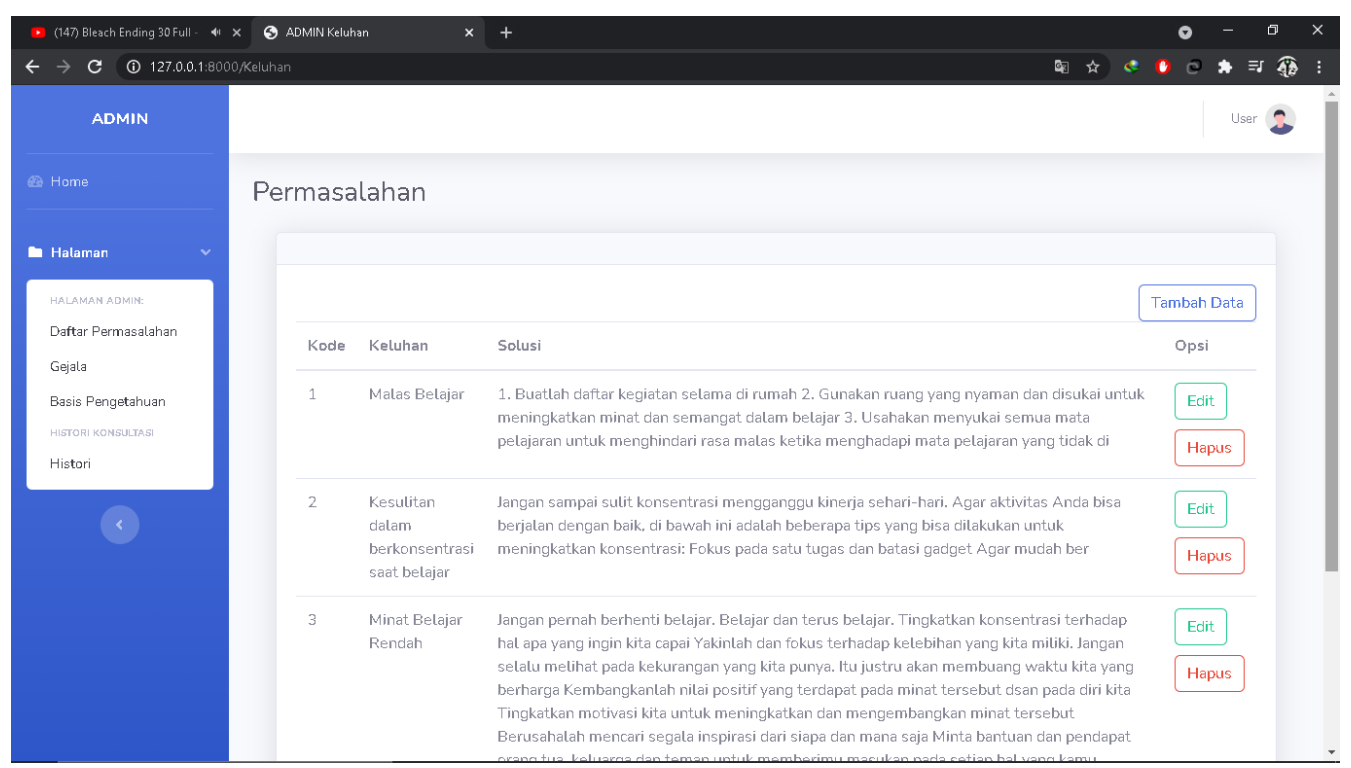

Gambar 4. Tampilan Halaman Kelola Data Permasalahan

\subsubsection{Tampilan Halaman Data Gejala Permasalahan}

Pada halaman ini Guru BK dapat melakukan input, edit, dan hapus data gejala permasalahan yang ditunjukkan pada Gambar 5 . 


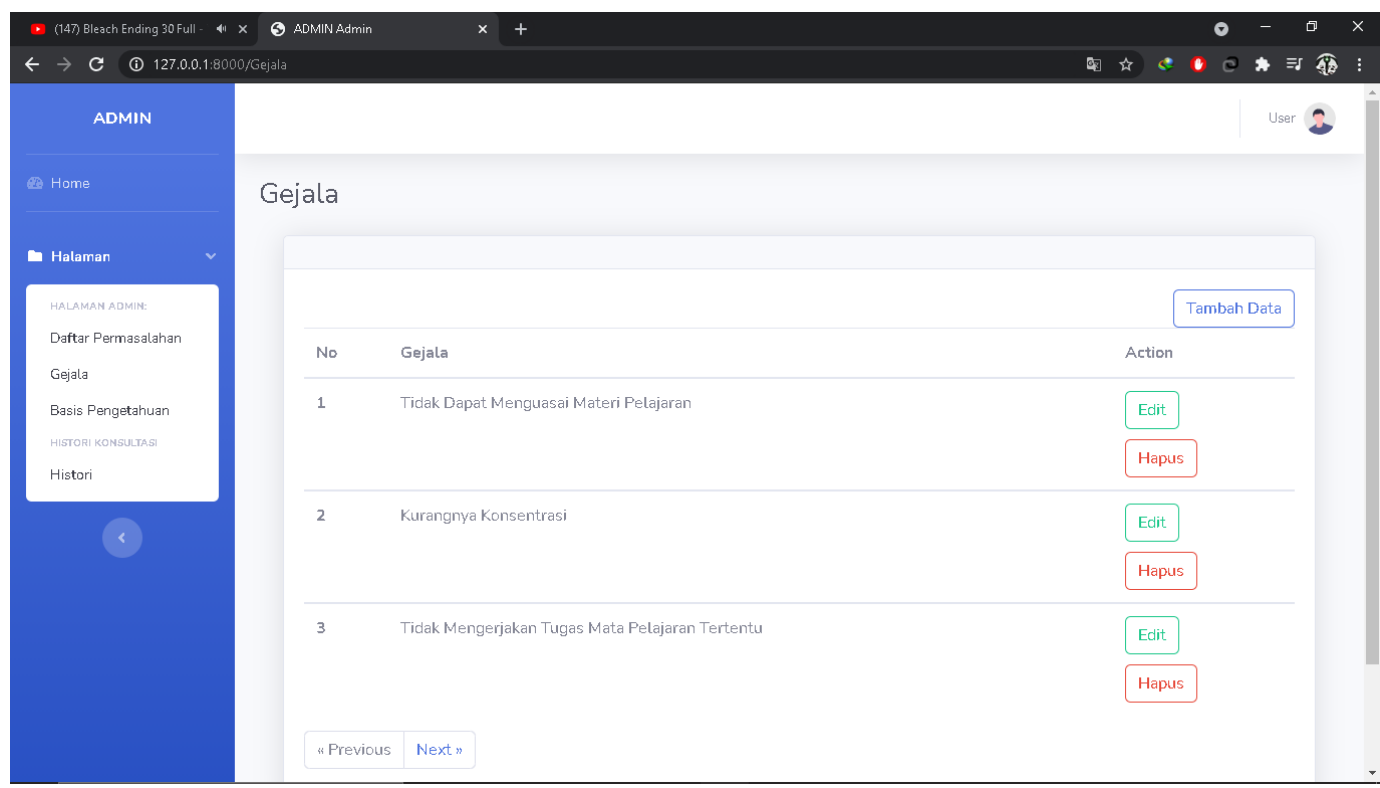

Gambar 5. Tampilan Halaman Gejala Permasalahan

\subsubsection{Tampilan Halaman Data Basis Pengetahuan}

Pada halaman ini Guru BK dapat melakukan input, edit, dan hapus data basis pengetahuan seperti bobot CF tiap-tiap gejala pada setiap jenis permasalahannya yang ditunjukkan pada Gambar 6.

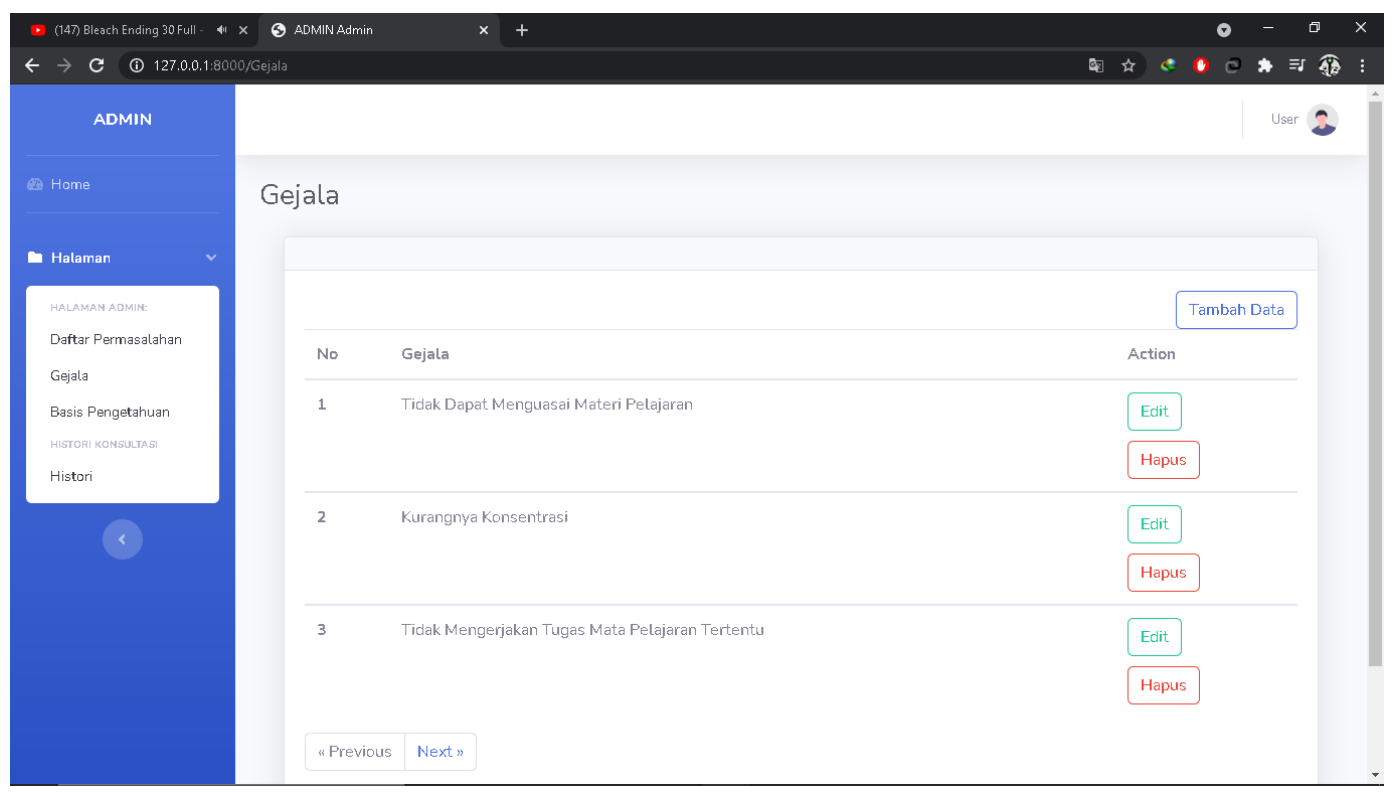

Gambar 6. Tampilan Halaman Gejala Permasalahan

\subsubsection{Tampilan Halaman Konseling}

Pada halaman konseling digunakan oleh siswa untuk konseling secara online terkait dengan masalah yang dihadapi. Pada halaman ini siswa terlebih dahulu mengisi nama dan kelas, serta ceklis masalah yang sekiranya sedang dihadapi oleh siswa yang ditunjukkan pada Gambar 7. 


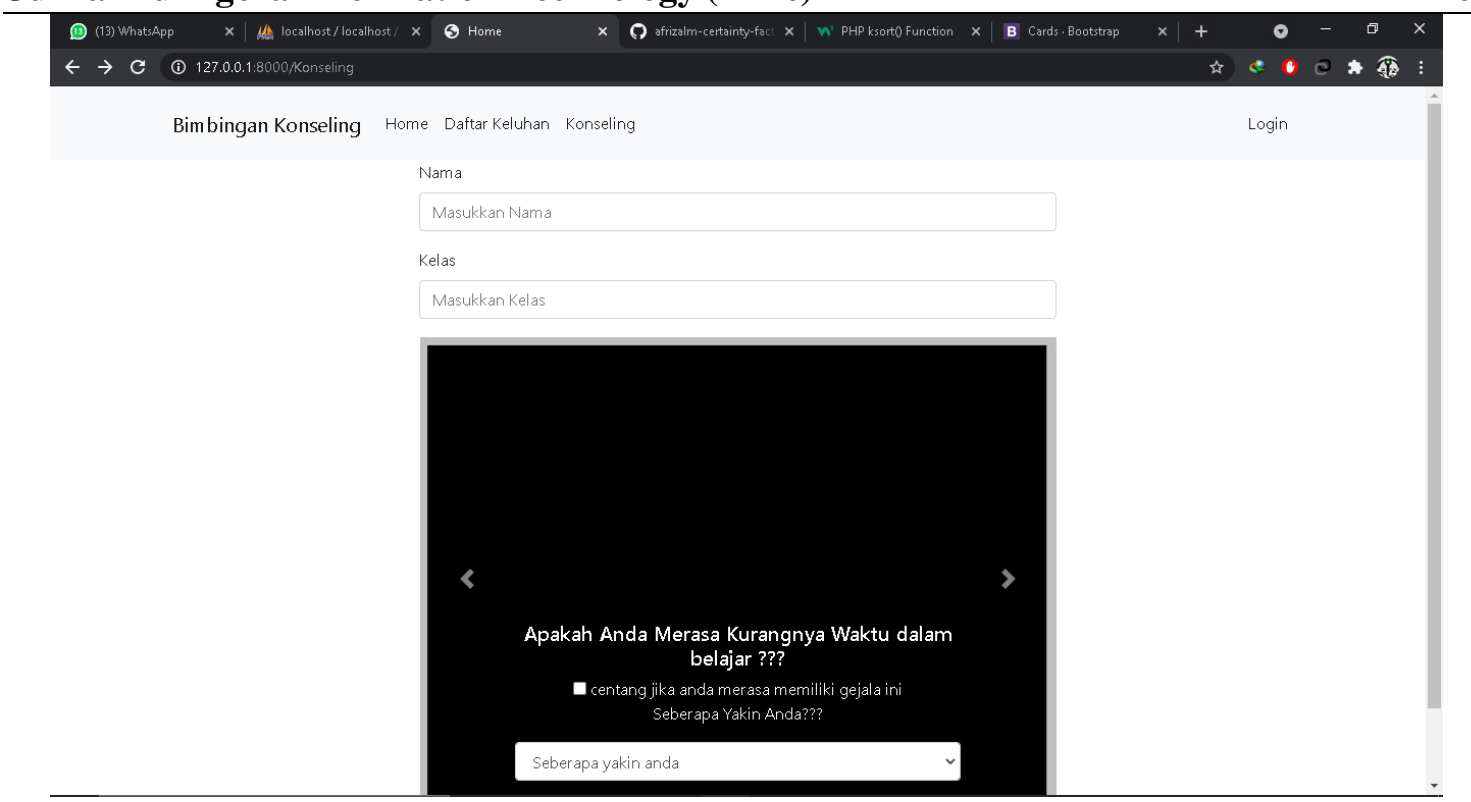

Gambar 7. Tampilan Halaman Konseling

\subsubsection{Tampilan Halaman Hasil Konseling}

Tampilan halaman hasil konseling digunakan siswa untuk melihat jenis permasalahan yang dihadapi berdasarkan gejala yang dipilih dan metode certainty factor melakukan proses perhitungan untuk menampilkan jenis permasalahan yang dihadapi berdasarkan persentase terbesar Gambar 8.

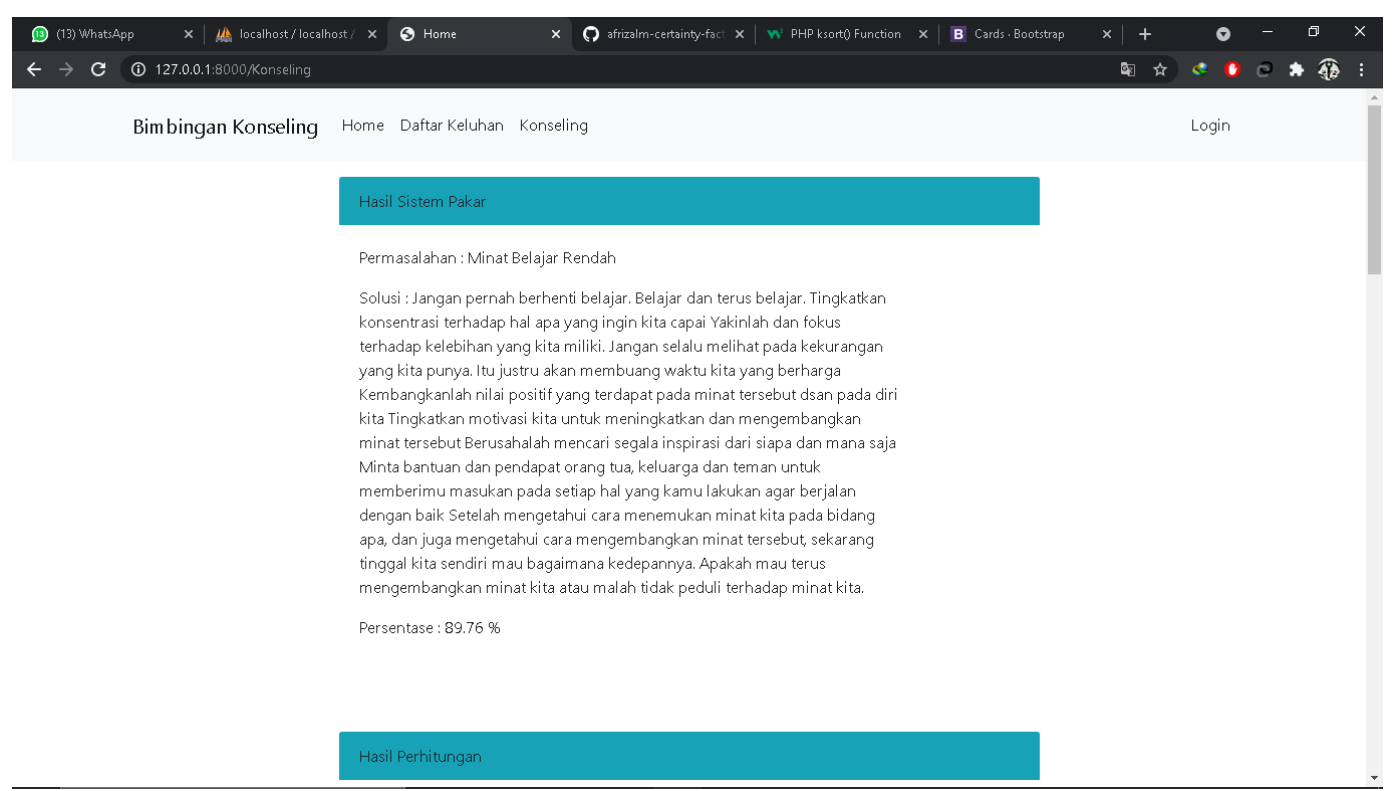

\subsection{Pengujian}

Gambar 8. Tampilan Halaman Hasil Konseling

Pada penelitian ini dilakukan pengujian usability menggunakan metode System Usability Scale (SUS) kepada siswa dan Guru BK untuk mengetahui tingkat kemudahan aplikasi yang dibuat. Berdasarkan hasil usability menggunakan SUS yang sudah diuji sebanyak 25 siswa SMP dan Guru BK Negeri 4 Mataram. Hasil pengujian usability kepada siswa mendapatkan skor sebesar 76.5\% dalam kategori Baik, sedangkan bagi Guru BK mendapatkan skor 92.70\% dalam kategori Sangat Baik.

https://journal.universitasbumigora.ac.id/index.php/bite ISSN: 2685-4066 


\section{Kesimpulan}

Aplikasi sistem pakar bimbingan konseling siswa bermasalah berbasis php dan mysql menggunakan metode certainty factor berhasil dibuat untuk mempermudah siswa melakukan konseling sehingga dapat mengetahui jenis permasalahan yang dihadapi beserta tingkat kepastiannya secara cepat. Pada aplikasi yang dibangun juga terdapat solusi atau saran yang dilakukan siswa berdasarkan jenis permasalahan yang dihadapi. Berdasarkan hasil pengujian usability menggunakan metode SUS dapat disimpulkan bahwa aplikasi bimbingan konseling siswa bermasalah mengunakan metode certainty factor memiliki tingkat kemudahan sebesar 76.5\% dalam kategori baik untuk siswa, sedangkan Guru BK memiliki tingkat kemudahan sebesar 92.70\% dalam kategori Sangat Baik. Saran untuk penelitian selanjutnya adalah menggunakan metode lainnya seperti fuzzy logic, dhamster shafer berbasis multi platform.

\section{Referensi}

[1] M. Dahria, "Pengembangan Sistem Pakar Dalam Membangun Suatu Aplikasi," Jurnal Saintikom, vol. 10, no. 3, pp. 199-205, 2011.

[2] H. Hairani, M. N. Abdillah, and M. Innuddin, "Perancangan Sistem Pakar Diagnosis Penyakit Rematik Menggunakan Inferensi Forward Chaining Berbasis Prolog," InfoTekJar (Jurnal Nasional Informatika dan Teknologi Jaringan), vol. 4, no. 1, pp. 811, 2019, doi: 10.30743/infotekjar.v4i1.1377.

[3] H. Hairani, M. N. Abdillah, and M. Innuddin, "An Expert System for Diagnosis of Rheumatic Disease Types Using Forward Chaining Inference and Certainty Factor Method," in 2019 International Conference on Sustainable Information Engineering and Technology (SIET), 2019, pp. 104-109.

[4] B. Dirgantara and H. Hairani, "Sistem Pakar Diagnosa Penyakit THT Menggunakan Inferensi Forward Chaining dan Metode Certainty Factor," Jurnal Bumigora Information Technology (BITe), vol. 3, no. 1, pp. 1-8, 2021, doi: 10.30812/bite.v3i1.1241.

[5] H. Hairani, K. Kurniawan, K. A. Latif, and M. Innuddin, "Metode Dempster-Shafer untuk Diagnosis Dini Jenis Penyakit Gangguan Jiwa Skizofrenia Berbasis Sistem Pakar," Sistemasi: Jurnal Sistem Informasi, vol. 10, no. 2, pp. 280-289, 2021, doi: 10.32520/stmsi.v10i2.1195.

[6] A. Sucipto, Y. Fernando, R. I. Borman, and N. Mahmuda, "Penerapan Metode Certainty Factor Pada Diagnosa Penyakit Saraf Tulang Belakang," Jurnal Ilmiah FIFO, vol. 10, no. 2, p. 18, 2019, doi: 10.22441/fifo.2018.v10i2.002.

[7] D. Daniel and G. Virginia, "Implementasi Sistem Pakar Untuk Mendiagnosis Penyakit Dengan Gejala Demam Menggunakan Metode Certainty Factor," Jurnal informatika, vol. 6, no. 1, pp. 12-23, 2010.

[8] S. Kusumadewi, Artificial Intelligence (Teknik dan Aplikasinya). Yogyakarta: Graha Ilmu, 2003.

[9] S. Sutojo, Mulyanto, Kecerdasan Buatan. Yogyakarta: Andi, 2011.

[10] K. Kusrini, Sistem Pakar Teori dan Aplikasi. Yogyakarta: Andi, 2006.

[11] I. A. H.N, P. I. Nugroho, and R. Ferdiana, "Pengujian Usability Website Menggunakan System Usability Scale," Jurnal Iptekkom: Jurnal Ilmu Pengetahuan \& Teknologi Informasi, vol. 17, no. 1, p. 31, Jun. 2015, doi: 10.33164/iptekkom.17.1.2015.31-38. 

ISSN: 2685-4066 